\title{
Basic Energy Efficiency of Plasma Production in Electrical Discharge and Electron Beam Reactors
}

\author{
B. M. Penetrante, M. C. Hsiao, \\ J. N. Bardsley, B. T. Merritt and G. E. Vogtlin \\ Lawrence Livermore National Laboratory, Livermore, CA
}

A. Kuthi

Plasma \& Materials Technologies, Inc., Chatsworth, CA 91311

C. P. Burkhart, J. R. Bayless

First Point Scientific, Inc., Agoura Hills, CA

This paper was prepared for submittal to the

Symposium on

Non-Thermal Plasma Technology for Air Contaminant Control

Tokyo, Japan

November 1, 1996

November 1, 1996

This is a preprint of a paper intended for publication in a journal or proceedings. Since changes may be made before publication, this preprint is made available with the understanding that it will not be cited or reproduced without the permission of the author. 


\section{DISCLAIMER}

This document was prepared as an account of work sponsored by an agency of the United States Government. Neither the United States Government nor the University of California nor any of their employees, makes any warranty, express or implied, or assumes any legal liability or responsibility for the accuracy, completeness, or usefulness of any information, apparatus, product, or process

disclosed, or represents that its use would not infringe privately owned rights. Reference herein to any specific commercial product, process, or service by trade name, trademark, manufacturer, or otherwise, does not necessarily constitute or imply its endorsement, recommendation, or favoring by the United States Government or the University of California. The views and opinions of authors expressed herein do not necessarily state or reflect those of the United States Government or the University of California, and shall not be used for advertising or product endorsement purposes. 
Symposium on

Non-Thermal Plasma Technology for Air Contaminant Control

November 1, 1996, Tokyo, Japan

\title{
BASIC ENERGY EFFICIENCY OF PLASMA PRODUCTION IN ELECTRICAL DISCHARGE AND ELECTRON BEAM REACTORS
}

\author{
B. M. Penetrante, M. C. Hsiao, \\ J. N. Bardsley, B. T. Merritt and G. E. Vogtlin \\ Lawrence Livermore National Laboratory, Livermore, CA 94550 \\ A. Kuthi \\ Plasma \& Materials Technologies, Inc., Chatsworth, CA 91311 \\ C. P. Burkhart and J. R. Bayless \\ First Point Scientific, Inc., Agoura Hills, CA 91301
}

\begin{abstract}
Non-thermal plasma processing is an emerging technology for the abatement of volatile organic compounds (VOCs) and nitrogen oxides $\left(\mathrm{NO}_{\mathrm{x}}\right)$ in atmosphericpressure gas streams. Either electrical discharge or electron beam methods can produce these plasmas. This paper presents a comparative assessment of various non-thermal plasma reactors. The goal of our work is two-fold: (1) to understand the feasibility and scalability of various non-thermal plasma reactors by focusing on the energy efficiency of the electron and chemical kinetics, and (2) to optimize process parameters and provide performance and economic data. Experimental results using a compact electron beam reactor, pulsed corona reactor and dielectric-barrier discharge will be presented. These reactors have been used to study the removal of $\mathrm{NO}_{\mathrm{x}}$ and a wide variety of VOCs. The effects of background gas composition and gas temperature on the decomposition chemistry have been studied. The decomposition mechanisms are discussed to illustrate how the chemistry could strongly affect the economics of the process. An analysis of the electron kinetics show that electrical discharge reactors are most suitable only for processes requiring $\mathrm{O}$ radicals. For pollution control applications requiring copious amounts of electrons, ions, $\mathrm{N}$ atoms or $\mathrm{OH}$ radicals, the use of electron beam reactors is generally the best way of minimizing the electrical power consumption.
\end{abstract}




\section{INTRODUCTION}

Non-thermal plasma processing is an emerging technology for the abatement of volatile organic compounds (VOCs), nitrogen oxides $\left(\mathrm{NO}_{\mathrm{x}}\right)$ or other hazardous air pollutants (HAPs) in atmospheric-pressure gas streams [1]. Either electrical discharge or electron beam methods can produce these plasmas. The basic principle that these techniques have in common is to produce a plasma in which a majority of the electrical energy goes into the production of energetic electrons, rather than into gas heating. Through electron-impact dissociation and ionization of the background gas molecules, the energetic electrons produce free radicals, ions and additional electrons which, in turn, oxidize, reduce or decompose the pollutant molecules. This is in contrast to the use of plasma furnaces or torches and several chemical techniques in which the whole gas is heated in order to break up the undesired molecules. For many applications, particularly in the removal of very dilute concentrations of air pollutants, the non-thermal plasma approach would be most appropriate because of its energy selectivity.

Electrical discharge and electron beam methods can both be implemented in many ways. There are many types of electrical discharge reactors, the variants depending on the electrode configuration and electrical power supply (pulsed, AC or DC). Some of the types of electrical discharge reactors that have been investigated for VOC abatement include the pulsed corona (Refs. 2-3), ferroelectric packed bed [2], dielectric-barrier discharge [3-6], surface discharge [7], gliding arc [8] and microwave discharge [9]. Two of the more extensively investigated types of discharge reactors are based on the pulsed corona and dielectric-barrier discharge. In the pulsed corona method, the reactor is driven by very short pulses of high voltage, thus creating short-lived discharge plasmas that consist of energetic electrons, which in turn produce the free radicals responsible for the decomposition of the undesirable molecules. In a dielectric barrier discharge reactor, one or both of the electrodes are covered with a dielectric layer, such as glass or alumina. Whereas in the pulsed corona method the transient behavior of the plasma is controlled by the applied voltage pulse, the plasma that takes place in a dielectric-barrier discharge selfextinguishes when charge build-up on the dielectric layer reduces the local electric field. Dielectric-barrier discharge reactors, also referred to as silent discharge reactors, are now routinely used to produce commercial quantities of ozone. Unfortunately, the plasma conditions suitable for the generation of ozone are not the same plasma conditions optimum for the destruction of most VOCs. Similarly, the plasma conditions suitable for the generation of ozone are not the same plasma conditions optimum for the chemical reduction of $\mathrm{NO}_{\mathrm{x}}$ (i.e., the conversion of $\mathrm{NO}_{\mathrm{x}}$ to the benign products $\mathrm{N}_{2}$ and $\mathrm{O}_{2}$.)

The application of electron beam method for $\mathrm{NO}_{\mathrm{x}}$ removal, by oxidation, in power plant flue gases has been investigated since the early 1970's in both laboratory- and pilot-scale experiments [10-13]. The electron beam method has also been applied to the removal of VOCs; for example, vinyl chloride [14], trichloroethylene [15-17], trichloroethane [17], carbon tetrachloride [18-20] and other types of volatile hydrocarbons encountered in industrial off-gases [20-21]. In the past, the high capital cost and x-ray hazard associated with conventional MeV-type 
electron beam accelerators have discouraged the use of electron beam processing in many pollution control applications. Recently, however, compact low-energy $(<200$ $\mathrm{keV}$ ) electron accelerators have been developed to meet the requirements of industrial applications such as crosslinking of polymer materials, curing of solventfree coatings, and drying of printing inks. Special materials have also been developed to make the window thin and rugged. Some of these compact electron beam sources are already commercially available and could be utilized for many pollution control applications. One example of such a compact electron beam source [22] is shown in Figure 1.

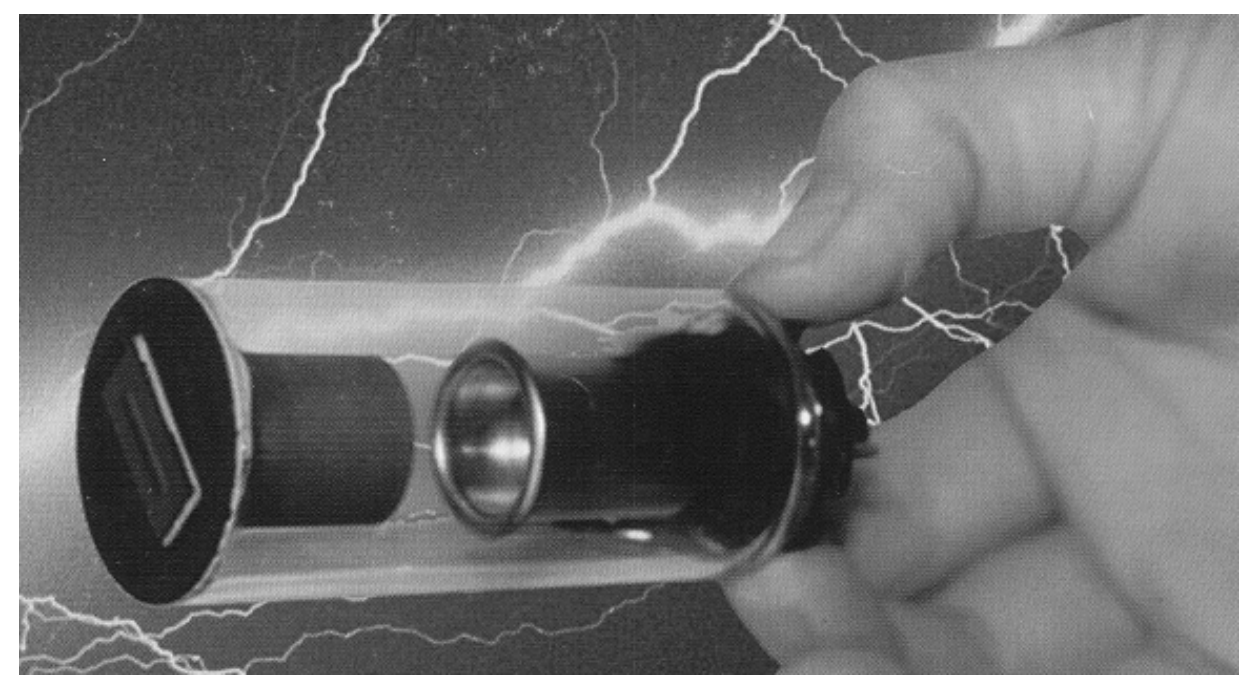

Figure 1. A compact electron beam source developed jointly by Lawrence Livermore National Laboratory and American International Technologies, Inc. The tube is a low cost alternative to large electron beam processing systems and does not require extensive x-ray shielding. The key technical challenge has been the development of a reliable thin membrane window capable of transmitting electron current densities of several milliamperes per square centimeter with $90 \%$ efficiency at 50 kilovolts. See R\&D Magazine, September 1995, p. 51 and p. 55.

In this paper we will present a comparative assessment of various nonthermal plasma reactors. The thrust of our work has been two-fold: (1) to understand the scalability of various non-thermal plasma reactors by focusing on the energy efficiency of the electron and chemical kinetics, and (2) to identify the byproducts to ensure that the effluent gases from the processor are either benign or much easier and less expensive to dispose of compared to the original pollutants. We will present experimental results using a compact electron beam reactor, pulsed corona reactor and dielectric-barrier discharge. We have used these reactors to study the removal of $\mathrm{NO}_{\mathrm{x}}$ in both reducing and oxidizing environments, and to the removal of a wide variety of VOCs. We have studied the effects of background gas composition and gas temperature on the decomposition chemistry. For all of the pollutants investigated, we find that electron beam processing is remarkably more energy efficient than electrical discharge processing. 


\section{TEST FACILITY}

All of our experiments were performed in a flow-through configuration. To characterize the energy consumption of the process for each VOC, the composition of the effluent gas was recorded as a function of the input energy density. The input energy density, Joules per standard liter, is the ratio of the power (deposited into the gas) to gas flow rate at standard conditions $\left(25^{\circ} \mathrm{C}\right.$ and $\left.1 \mathrm{~atm}\right)$. The amount of VOC was quantified using an FTIR analyzer and a gas chromatograph.

Our electron beam reactor, shown schematically in Figure 2, used a cylindrical electron gun designed to deliver a cylindrically symmetric electron beam that is projected radially inward through a $5 \mathrm{~cm}$ wide annular window into a $17 \mathrm{~cm}$ diameter flow duct. An electron beam of $125 \mathrm{keV}$ energy was introduced into the reaction chamber through a 0.7 mil thick titanium window. The electron beam current was produced from a low-pressure helium plasma in an annular vacuum chamber surrounding the flow duct. This novel design facilitates highly uniform (efficient) irradiation of the flowing gas. The non-plasma produced by the electron beam is capable of decomposing the VOCs in polluted gas streams at high flow rates.

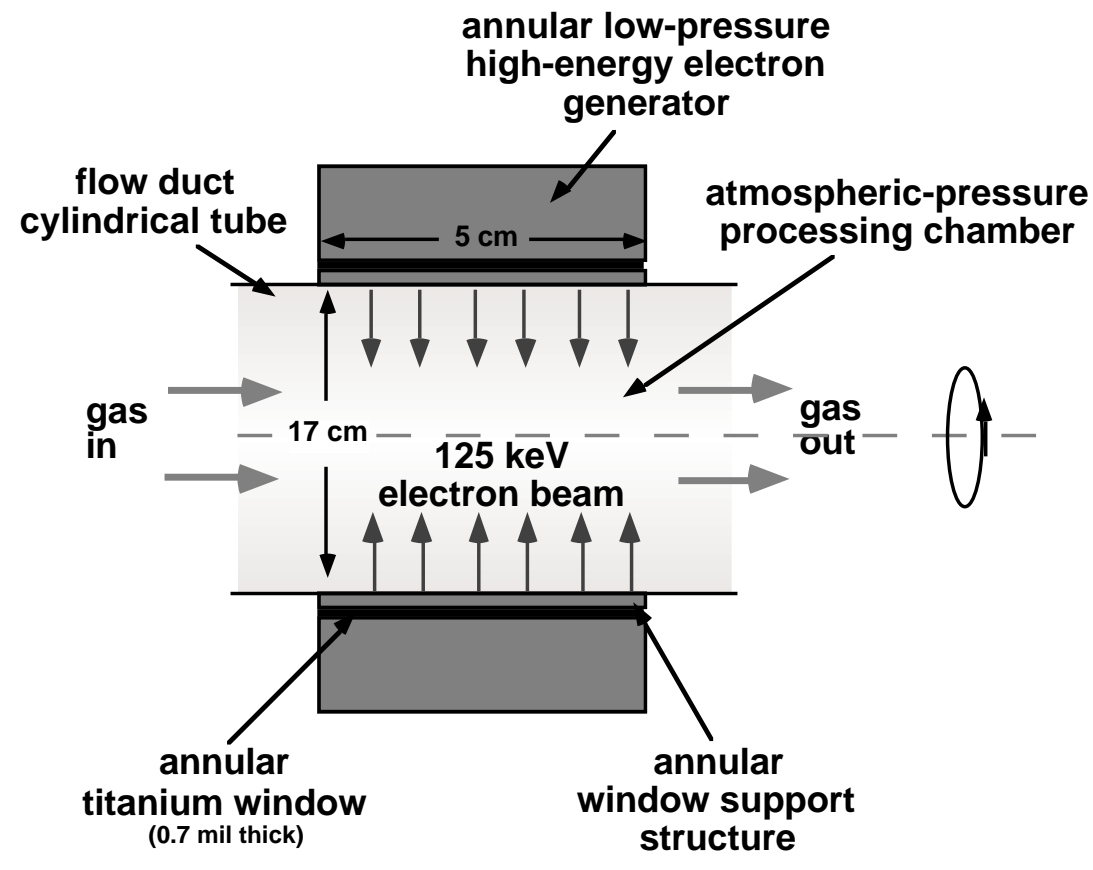

Figure 2. Schematic of the compact electron beam reactor developed by First Point Scientific, Inc. The cylindrical electron gun is designed to deliver a cylindricallysymmetric highly-uniform electron beam that is projected radially inward into the gas flow duct.

Our pulsed corona reactor is a $1.5 \mathrm{~mm}$ diameter wire in a $60 \mathrm{~mm}$ diameter metal tube $300 \mathrm{~mm}$ long. The power supply is a magnetic pulse compression system capable of delivering up to $15-35 \mathrm{kV}$ output into $100 \mathrm{~ns}$ FWHM pulses at repetition 
rates from $15 \mathrm{~Hz}$ to $1.5 \mathrm{kHz}$. The power input to the processor was varied by changing either the pulse energy or pulse repetition frequency. For the same energy density input, either method produced almost identical results. The gas mixtures were set with mass flow controllers. The gas and processor temperatures can be maintained at a temperature that can be controlled from $25^{\circ} \mathrm{C}$ to $300^{\circ} \mathrm{C}$.

We investigated whether it is possible to improve the processing efficiency by taking advantage of transient high electric fields during the formation of the streamer plasma. To do this, the voltage pulse should be very fast-rising, but with a pulse length short enough so that most of the radical production occurs only during streamer propagation. One way of achieving this condition is by combining the fastrising, strongly non-uniform applied electric field of a corona reactor with the selfextinguishing microdischarge pulses of a dielectric-barrier discharge reactor. We therefore used a reactor that is a form of hybrid between a pulsed corona reactor and a dielectric-barrier discharge reactor. The reactor consisted of a wire $(1.5 \mathrm{~mm}$ diameter) in a $300 \mathrm{~mm}$ long dielectric (alumina) tube with inner and outer diameters of $28 \mathrm{~mm}$ and $35 \mathrm{~mm}$, respectively. The middle $150 \mathrm{~mm}$ of the dielectric tube has aluminum foil coating the outside to form the outer electrode.

\section{ELECTRON AND CHEMICAL KINETICS CALCULATIONS}

To calculate the ion and radical production yields by electrical discharge processing, we used the Boltzmann code ELENDIF [23] to calculate electron energy deposition. ELENDIF uses as input the specified gas composition and the electronmolecule collision cross sections. To calculate the ion and radical production yields by electron beam processing, we used the code DEGRAD [24]. DEGRAD also uses as input the specified gas composition and the electron-molecule collision cross sections. This code follows typical electrons as they perform successive collisions, and discrete energy bins are used to represent the energy degradation of an electron from a given beam energy. The procedure records the number of excitations, dissociations and ionizations, and the total number of all orders of secondary electrons. The chemical kinetics describing the subsequent interaction of the ions and radicals with the exhaust gas was studied using CHEMKIN-II [25].

\section{RESULTS AND DISCUSSION}

Whatever the type of reactor, the plasma can induce four basic types of reactions with the pollutant molecules, as shown in Figure 3. The electron mean energy in a plasma reactor is very important because it determines the types of radicals produced in the plasma and the input electrical energy required to produce those radicals. Figure 4-(a) shows the dissipation of the input electrical power in a dry air discharge. Note that at low electron mean energies $(<5 \mathrm{eV})$ a large fraction of the input electrical energy is consumed in the vibrational excitation of $\mathrm{N}_{2}$. Electron mean energies around $5 \mathrm{eV}$ are optimum for the electron-impact dissociation of $\mathrm{O}_{2}$, which is important for the production of $\mathrm{O}$ radicals. These oxidizing radicals play a key role in the generation of ozone and the initial decomposition of some types of VOCs. For VOCs that take advantage of electron-induced or ion-induced 
decomposition, high electron mean energies are required to efficiently implement the ionization of the background gas.

- Oxidation

- Reduction

$$
\begin{gathered}
\mathrm{e}+\mathrm{O}_{2}=\mathrm{e}+\mathrm{O}\left({ }^{3} \mathrm{P}\right)+\mathrm{O}\left({ }^{1} \mathrm{D}\right) \\
\mathrm{O}\left({ }^{3} \mathrm{P}\right)+\mathrm{NO}+\mathrm{M}=>\mathrm{NO}{ }_{2}+\mathrm{M} \\
\mathrm{O}\left({ }^{1} \mathrm{D}\right)+\mathrm{H}_{2} \mathrm{O}=>\mathrm{OH}+\mathrm{OH} \\
\mathrm{OH}+\mathrm{NO}_{2}=>\mathrm{HNO}_{3}
\end{gathered}
$$

$$
\begin{aligned}
\mathrm{e}+\mathrm{N}_{2} & =\mathrm{e}+\mathrm{N}+\mathrm{N} \\
\mathrm{N} & +\mathrm{NO}=>\mathrm{N}_{2}+\mathrm{O}
\end{aligned}
$$

- Electron-induced decomposition

$$
\begin{aligned}
\mathrm{e}+\mathrm{N}_{2} & =>\mathrm{e}+\mathrm{e}+\mathrm{N}_{2}^{+} \\
\mathrm{e}+\mathrm{O}_{2} & =>\mathrm{e}+\mathrm{e}+\mathrm{O}_{2}^{+} \\
\mathrm{e} & +\mathrm{CCl}_{4}=>\mathrm{CCl}_{3}+\mathrm{Cl}^{-}
\end{aligned}
$$

- Ion-induced decomposition

$$
\mathrm{N}_{2}{ }^{+}+\mathrm{CH}_{3} \mathrm{OH}=>\mathrm{CH}_{3}{ }^{+}+\mathrm{OH}+\mathrm{N}_{2}
$$

Figure 3. The plasma can induce four basic types of reactions with the pollutant molecules.

The rate coefficients for electron-impact dissociation and ionization reactions strongly depend on the electron energy distribution in the plasma. In pulsed corona and dielectric-barrier discharge reactors, the non-thermal plasma is produced through the formation of statistically distributed microdischarges. The electrons dissociate and ionize the background gas molecules within nanoseconds in the narrow channel formed by each microdischarge. The electron energy distribution in the plasma is complicated because the electric field is strongly non-uniform (e.g. because of strong space-charge field effects) and time dependent. However, most of the species responsible for the chemical processing are generated in the microdischarge channels already established during the main current flow. In each microdischarge column, the electrons acquire a drift velocity, $\mathrm{v}_{\mathrm{d}}$, and an average energy corresponding to an effective $\mathrm{E} / \mathrm{n}$, i.e., the value of the electric field $\mathrm{E}$ divided by the total gas density $n$. The efficiency for a particular electron-impact process can be expressed in terms of the G-value (number of dissociation or ionization reactions per $100 \mathrm{eV}$ of input energy) defined as

$$
\mathrm{G} \text {-value }=100 \mathrm{k} /\left(\mathrm{v}_{\mathrm{d}} \mathrm{E} / \mathrm{n}\right)
$$

where $\mathrm{k}$ is the rate coefficient $\left(\mathrm{cm}^{3} /\right.$ molec-s). The rate coefficient $\mathrm{k}$ represents the number of reactions in a unit volume per unit time. The quantity $v_{d} E / n$ represents the amount of energy expended by the electrons in a unit volume per 
unit time. In Figure 4-(b) the calculated G-values for various electron-impact dissociation and ionization processes in dry air are shown as functions of the electron mean energy in the discharge plasma.
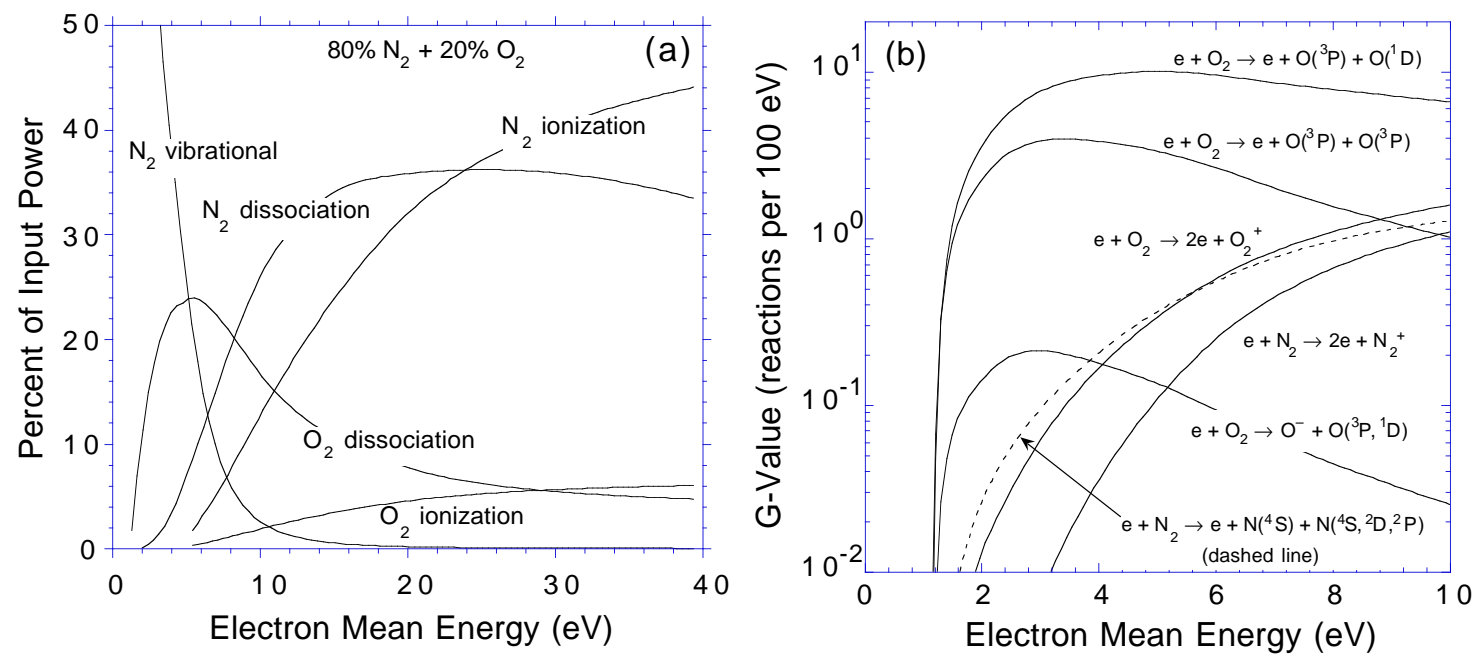

Figure 4. (a) Electrical power dissipation in a dry air discharge, showing the percent of input power consumed in the electron-impact processes leading to vibrational excitation, dissociation and ionization of $\mathrm{N}_{2}$ and $\mathrm{O}_{2}$. (b) Calculated G-values (number of reactions per $100 \mathrm{eV}$ of input energy) for dissociation and ionization processes in dry air, shown as functions of the electron mean energy in a discharge plasma.

Under most conditions encountered in pulsed corona or dielectric-barrier discharge processing, the effective $\mathrm{E} / \mathrm{n}$ is close to the value for breakdown (Paschen field) [26-27]. For dry air, the effective $\mathrm{E} / \mathrm{n}$ is around $130 \mathrm{Td}\left(1 \mathrm{Td}=10^{-17} \mathrm{~V}-\mathrm{cm}^{2}\right)$, which corresponds to an electron mean energy of about $4 \mathrm{eV}$. Our analysis suggests that the attainable electron mean energy in electrical discharge reactors is rather limited. There are two ways of increasing the electron mean energy in electrical discharge reactors: (1) use very narrow gap spacings (100 microns or less) to increase the breakdown $\mathrm{E} / \mathrm{n}$ for the same applied voltage, or (2) use very fast rising voltage pulses (10 nanoseconds or less risetime) to increase the breakdown $\mathrm{E} / \mathrm{n}$ for typical gap spacings. In the case of very fast rising voltage pulses, the breakdown $\mathrm{E} / \mathrm{n}$ could increase to about twice the normal breakdown $\mathrm{E} / \mathrm{n}$, i.e. around $300 \times 10^{-17} \mathrm{~V}-\mathrm{cm}^{2}$, which corresponds to an electron mean energy of around $7 \mathrm{eV}$. A reasonable upper limit for the effective $\mathrm{E} / \mathrm{n}$ is $400 \times 10^{-17} \mathrm{~V}-\mathrm{cm}^{2}$ for an extremely fast rising voltage pulse; this condition corresponds to an electron mean energy of about $9 \mathrm{eV}$. 

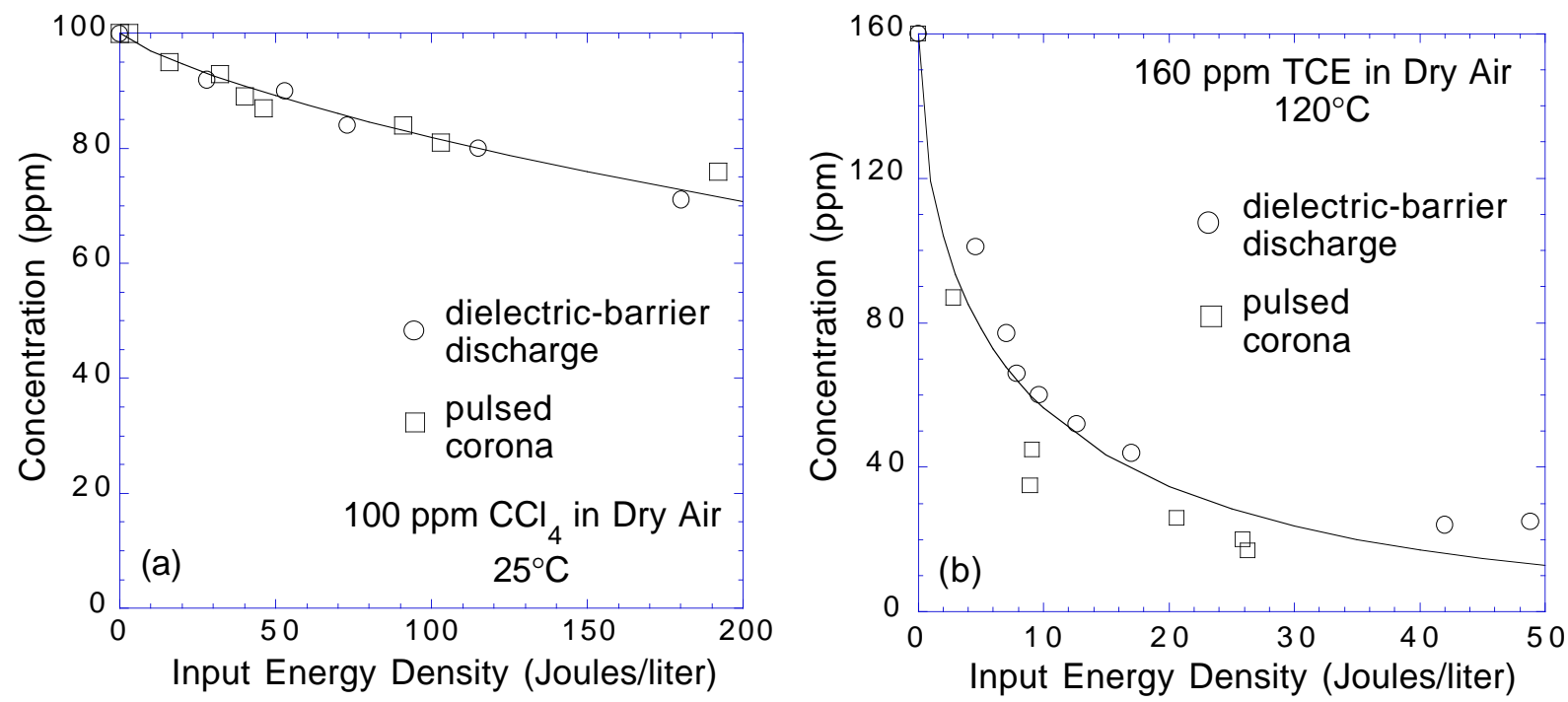

Figure 5. Pulsed corona and dielectric-barrier discharge processing of (a) $100 \mathrm{ppm}$ carbon tetrachloride in dry air at $25^{\circ} \mathrm{C}$ and (b) $160 \mathrm{ppm}$ trichloroethylene in dry air at $120^{\circ} \mathrm{C}$. There is no significant difference in the performance of different types of electrical discharge reactors.
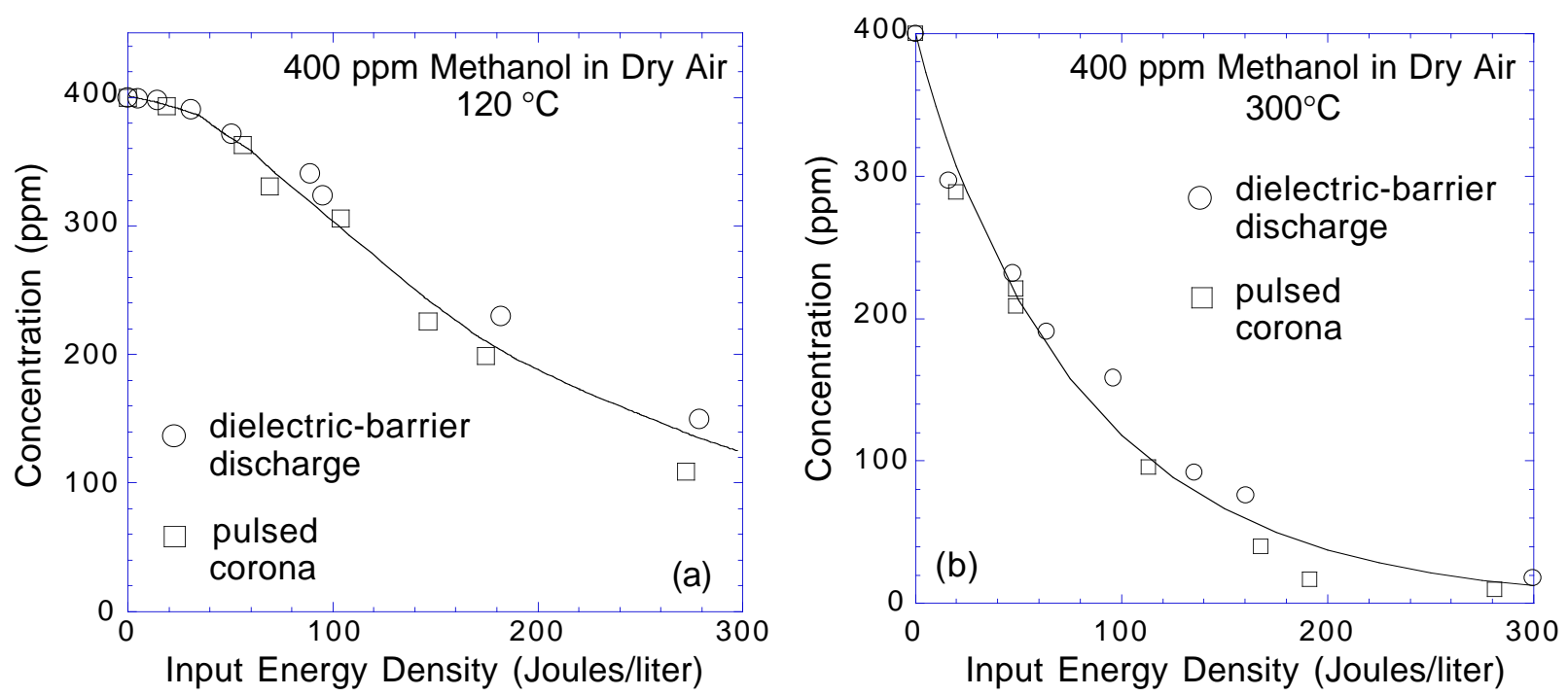

Figure 6. Pulsed corona and dielectric-barrier discharge processing of $400 \mathrm{ppm}$ methanol in dry air at (a) $120^{\circ} \mathrm{C}$ and (b) $300^{\circ} \mathrm{C}$. There is no significant difference in the performance of different types of electrical discharge reactors.

Under identical gas conditions (gas composition and gas temperature), we see no significant difference in the energy efficiency of various types of electrical discharge reactors. Figure 5-(a) shows the comparison between pulsed corona and dielectric-barrier discharge processing of carbon tetrachloride in dry air at $25^{\circ} \mathrm{C}$. Figure 5-(b) shows the comparison between pulsed corona and dielectric-barrier 
discharge processing of trichloroethylene in dry air at $120^{\circ} \mathrm{C}$. Figures 6-(a) and 6-(b) shows the comparison between pulsed corona and dielectric-barrier discharge processing of methanol in dry air at $120^{\circ} \mathrm{C}$ and $300^{\circ} \mathrm{C}$. We now have considerable experimental evidence showing that all discharge reactors have the same basic energy consumption under identical gas conditions [3, 27].

Figure 7-(a) shows a comparison between electron beam, pulsed corona and dielectric-barrier discharge processing of $100 \mathrm{ppm}$ carbon tetrachloride $\left(\mathrm{CCl}_{4}\right)$ in dry air at $25^{\circ} \mathrm{C}$. The rate limiting step in the decomposition of $\mathrm{CCl}_{4}$ is determined by the dissociative attachment of $\mathrm{CCl}_{4}$ to the thermalized electrons in the created plasma [18-19]:

$$
\mathrm{e}+\mathrm{CCl}_{4} \rightarrow \mathrm{Cl}^{-}+\mathrm{CCl}_{3} .
$$

During the creation of the plasma, electron-ion pairs are produced through primary electron-impact ionization of the bulk molecules, such as e $+\mathrm{N}_{2}=>\mathrm{e}+\mathrm{N}_{2}+$ and e + $\mathrm{O}_{2}=>\mathrm{e}+\mathrm{O}_{2}{ }^{+}$, and the corresponding dissociative ionization processes for $\mathrm{N}_{2}$ and $\mathrm{O}_{2}$. An analysis of the rates of the reactions discussed above suggests that the energy consumption for $\mathrm{CCl}_{4}$ removal is determined by the energy consumption for creating electron-ion pairs. The energy density required to decompose $\mathrm{CCl}_{4}$ by $90 \%$ is around 20 Joules/liter and 1270 Joules/liter by electron beam and electrical discharge processing, respectively. This result demonstrates that for VOCs requiring copious amounts of electrons for decomposition, electron beam processing is much more energy efficient than electrical discharge processing. The main products in the plasma processing of $\mathrm{CCl}_{4}$ in air are $\mathrm{Cl}_{2}, \mathrm{COCl}_{2}$ and $\mathrm{HCl}$. These products can be easily removed from the gas stream; e.g. they dissolve and/or dissociate in aqueous solutions and combine with $\mathrm{NaHCO}_{3}$ in a scrubber solution to form $\mathrm{NaCl}$ [28].
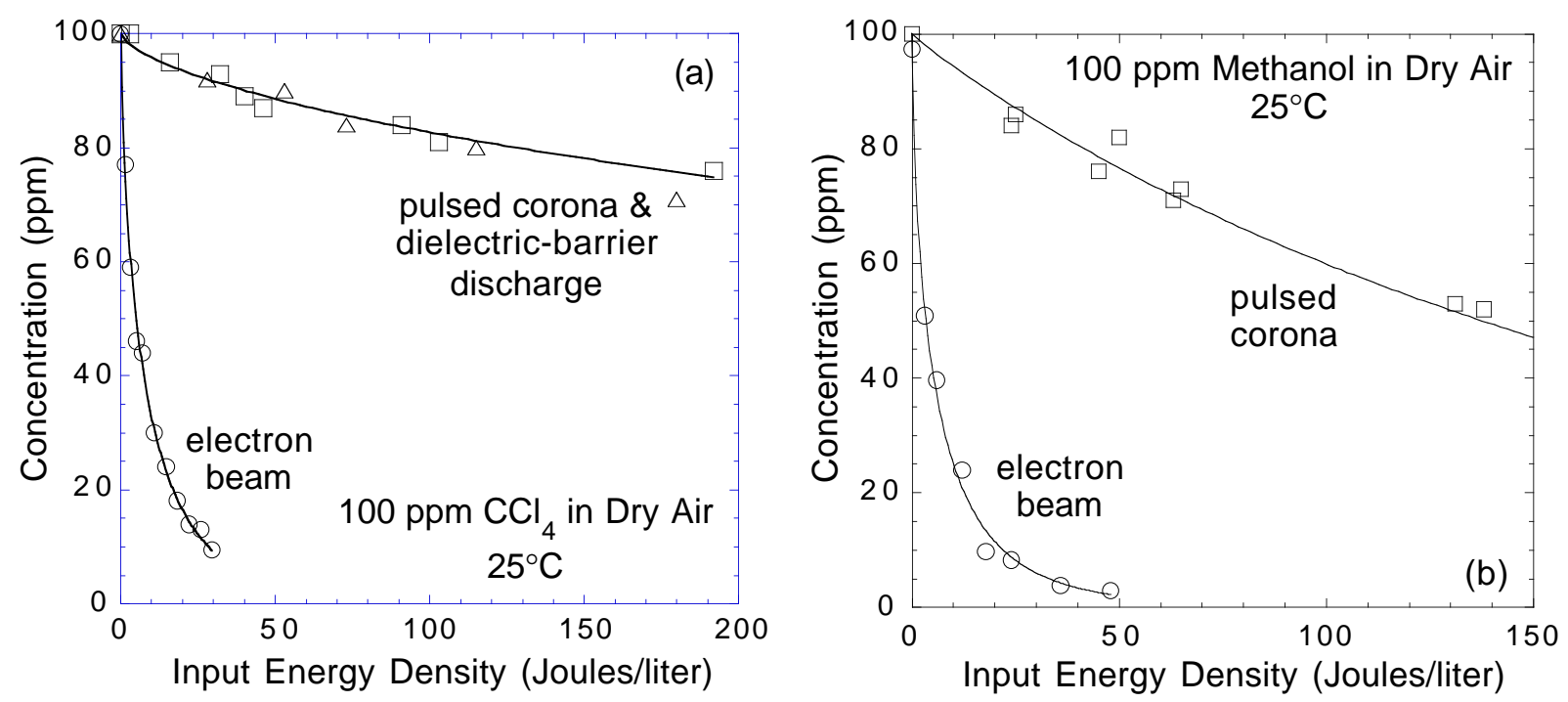

Figure 7. (a) Electron beam, pulsed corona and dielectric-barrier discharge processing of $100 \mathrm{ppm}$ carbon tetrachloride in dry air at $25^{\circ} \mathrm{C}$. (b) Electron beam and pulsed corona processing of $100 \mathrm{ppm}$ methanol in dry air at $25^{\circ} \mathrm{C}$. Electron beam processing is much more energy efficient compared to electrical discharge processing. 
Figure 7-(b) shows a comparison between electron beam and pulsed corona processing of $100 \mathrm{ppm}$ methanol in dry air at $25^{\circ} \mathrm{C}$. For the case of methanol, the electron beam method is more efficient because the decomposition proceeds mainly via a dissociative charge exchange reaction

$$
\mathrm{N}_{2}{ }^{+}+\mathrm{CH}_{3} \mathrm{OH} \rightarrow \mathrm{CH}_{3}{ }^{+}+\mathrm{OH}+\mathrm{N}_{2}
$$

The $\mathrm{OH}$ radicals resulting from the initial decomposition reaction (3) in turn may lead to additional decomposition of methanol via $\mathrm{OH}+\mathrm{CH}_{3} \mathrm{OH}$. To verify that the primary decomposition during electron beam processing does not proceed through an oxidation pathway using $\mathrm{O}$ radicals, we performed the experiment using $\mathrm{N}_{2}$ as the background gas; the specific energy consumption for electron beam processing in dry air is almost identical to that in $\mathrm{N}_{2}$.

Not all compounds have strong dissociative electron attachment or dissociative ion charge exchange rates. Figure 8-(a) shows a comparison between electron beam and pulsed corona processing of $100 \mathrm{ppm}$ methylene chloride $\left(\mathrm{CH}_{2} \mathrm{Cl}_{2}\right)$ in dry air at $25^{\circ} \mathrm{C}$. For methylene chloride, the dissociative attachment rate to electrons is many orders of magnitude lower compared to carbon tetrachloride. In this case, the electron beam method is also more efficient because the initial decomposition proceeds via a reaction with the $\mathrm{N}$ atom

$$
\mathrm{N}+\mathrm{CH}_{2} \mathrm{Cl}_{2} \rightarrow \text { products }
$$

The energy efficiency for dissociation of $\mathrm{N}_{2}$ to produce $\mathrm{N}$ atoms is much higher in an electron beam reactor.
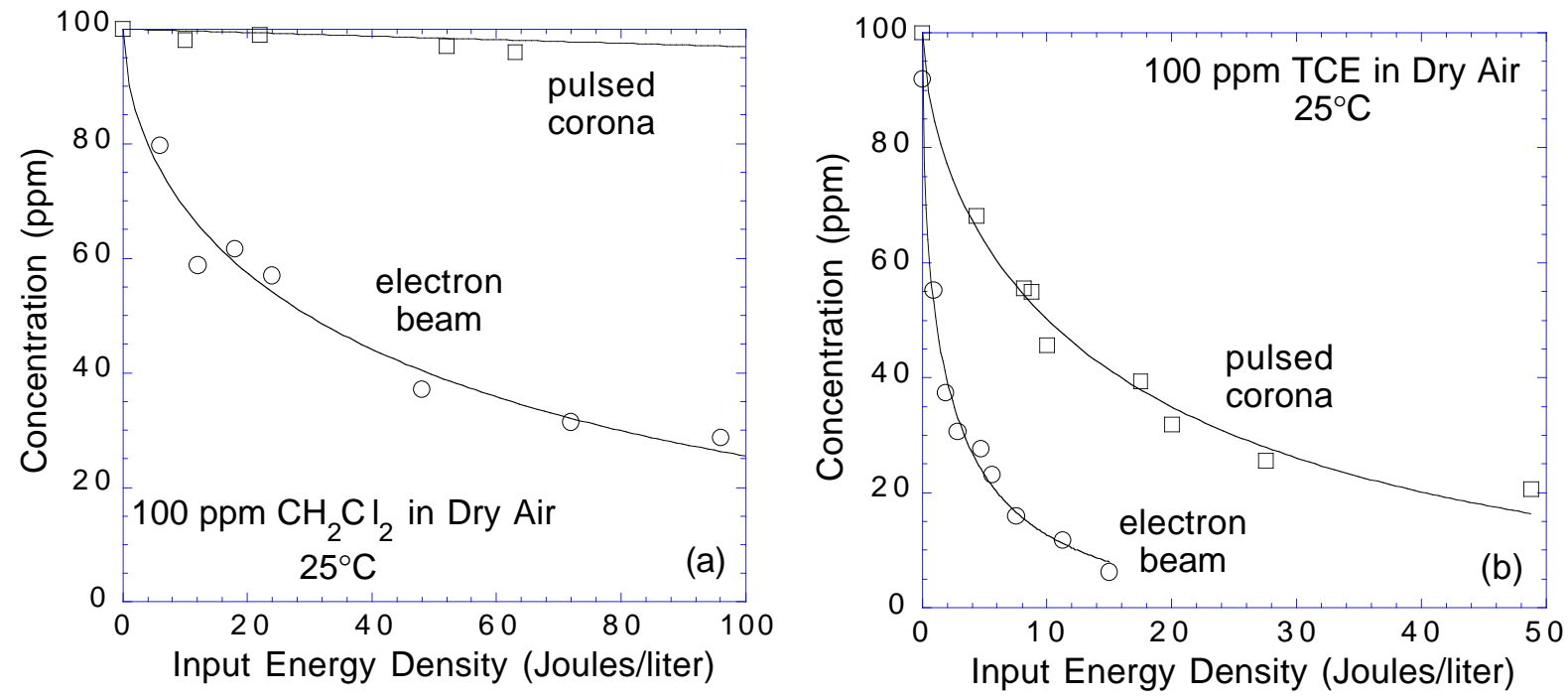

Figure 8. Comparison between electron beam and pulsed corona processing of 100 ppm of (a) methanol and (b) trichloroethylene in dry air at $25^{\circ} \mathrm{C}$. Electron beam processing is much more energy efficient compared to electrical discharge processing. 
For the case of trichloroethylene $\left(\mathrm{C}_{2} \mathrm{HCl}_{3}\right.$ or TCE), the initial decomposition pathway can proceed efficiently by reactions with either electrons (in the electron beam method) or $\mathrm{O}$ radicals (in the electrical discharge method). Figure 8-(b) compares electron beam and pulsed corona processing of $100 \mathrm{ppm}$ trichloroethylene in dry air at $25^{\circ} \mathrm{C}$. The energy consumption for TCE removal is relatively small using either electron beam or electrical discharge methods. This is because of a chain reaction mechanism involving chlorine $(\mathrm{Cl})$ radicals. The reaction of TCE with electrons or $\mathrm{O}$ radicals initiates the detachment of $\mathrm{Cl}$ radicals. Other TCE molecules then decompose by $\mathrm{Cl}$ radical addition to the carbon-carbon double bond

$$
\mathrm{Cl}+\mathrm{CHClCCl}_{2} \rightarrow \text { products }
$$

The decomposition pathway (5) regenerates more $\mathrm{Cl}$ radicals, which react with other TCE molecules, causing a chain reaction. Our byproduct measurements and material balance analysis point to significant amounts of dichloroacetyl chloride (DCAC), phosgene, and hydrochloric acid in addition to smaller amounts of $\mathrm{CO}$ and $\mathrm{CO}_{2}$ in the effluent.

The case of trichloroethane $\left(\mathrm{C}_{2} \mathrm{H}_{2} \mathrm{Cl}_{3}\right.$ or TCA) is interesting in comparison to TCE. TCA and TCE have very similar electron attachment cross sections, yet the energy required for decomposition of TCE by electron beam processing is more than 10 times less than for TCA. The TCA molecule decomposes primarily through hydrogen abstraction by chlorine and oxygen radicals, whereas the TCE molecule decomposes through chlorine and oxygen radical addition to the carbon-carbon double bond. The carbon-carbon single bond in TCA is not susceptible to chlorine radical attack. The chain reaction mechanism possible with chlorinated ethylenes therefore does not occur with chlorinated ethanes (Ref. 15).

The above decomposition mechanisms provide examples of how the chemistry could strongly affect the economics of the process. In some cases it will be necessary to experimentally or theoretically obtain fundamental information on rate constants and branching ratios in order to understand the energy consumption and byproduct formation in the plasma process. Computer modeling of the plasma chemical kinetics serves as an important design tool for minimizing the energy consumption of the process and identifying all possible byproducts.

Tables I and II show why electron beam processing is much more effective than electrical discharge processing in decomposing VOCs. Table I shows a comparison of the calculated G-values (number of reactions per $100 \mathrm{eV}$ of input energy) for dissociation processes in dry air using an electron beam and a discharge reactor. Discharge plasma conditions are optimum for the dissociation of $\mathrm{O}_{2}$, whereas electron beam conditions are optimum for the dissociation of $\mathrm{N}_{2}$. Table II shows a comparison of the calculated G-values for ionization processes in dry air using an electron beam and a discharge reactor. The efficiency for production of electron-ion pairs is much higher in an electron beam reactor compared to that in an electrical discharge reactor. 
Table I. Calculated G-values for dissociation processes in dry air using an electron beam and an electrical discharge reactor.

\begin{tabular}{|c|c|c|}
\hline REACTION & Electron Beam & Discharge \\
\hline $\mathrm{e}+\mathrm{N}_{2} \rightarrow \mathrm{e}+\mathrm{N}\left({ }^{4} \mathrm{~S}\right)+\mathrm{N}\left({ }^{4} \mathrm{~S},{ }^{2} \mathrm{D},{ }^{2} \mathrm{P}\right)$ & 1.2 & 0.17 \\
\hline $\mathrm{e}+\mathrm{O}_{2} \rightarrow \mathrm{e}+\mathrm{O}\left({ }^{3} \mathrm{P}\right)+\mathrm{O}\left({ }^{3} \mathrm{P}\right)$ & 1.3 & 4.0 \\
\hline $\mathrm{e}+\mathrm{O}_{2} \rightarrow \mathrm{e}+\mathrm{O}\left({ }^{3} \mathrm{P}\right)+\mathrm{O}\left({ }^{1} \mathrm{D}\right)$ & 2.65 & 10.0 \\
\hline $\mathrm{e}+\mathrm{O}_{2} \rightarrow \mathrm{O}^{-}+\mathrm{O}\left({ }^{3} \mathrm{P},{ }^{1} \mathrm{D}\right)$ & 0.11 & 0.19 \\
\hline
\end{tabular}

Table II. Calculated G-values for ionization processes in dry air using an electron beam and an electrical discharge reactor.

\begin{tabular}{|c|c|c|}
\hline REACTION & Electron Beam & Discharge \\
\hline $\mathrm{e}+\mathrm{N}_{2} \rightarrow 2 \mathrm{e}+\mathrm{N}\left({ }^{4} \mathrm{~S},{ }^{2} \mathrm{D}\right)+\mathrm{N}^{+}$ & 0.69 & $<10^{-6}$ \\
\hline $\mathrm{e}+\mathrm{N}_{2} \rightarrow 2 \mathrm{e}+\mathrm{N}_{2}{ }^{+}$ & 2.27 & 0.044 \\
\hline $\mathrm{e}+\mathrm{O}_{2} \rightarrow 2 \mathrm{e}+\mathrm{O}_{2}{ }^{+}$ & 2.07 & 0.17 \\
\hline $\mathrm{e}+\mathrm{O}_{2} \rightarrow 2 \mathrm{e}+\mathrm{O}\left({ }^{1} \mathrm{D}\right)+\mathrm{O}^{+}$ & 1.23 & 0.0016 \\
\hline
\end{tabular}

There are basically two types of reactions responsible for the depletion of NO by non-thermal plasmas: oxidation and reduction. In power plant flue gas treatment applications, the purpose of the plasma is to oxidize NO. The plasma produces $\mathrm{OH}$ radicals that play the major role in the simultaneous oxidation of $\mathrm{NO}$ and $\mathrm{SO}_{2}$ to their respective acids. The presence of $\mathrm{SO}_{2}$ lowers the power requirement of the oxidation process by recycling the $\mathrm{OH}$ radicals (see Figure 9). The presence of $\mathrm{O}$ radicals provide additional oxidation of $\mathrm{NO}$ to $\mathrm{NO}_{2}$; the latter is then further oxidized by $\mathrm{OH}$ radicals to nitric acid. The desired products, in the form of ammonium salts, are then obtained by mixing ammonia with the formed acids. Some form of scrubbing is required to collect the final products.

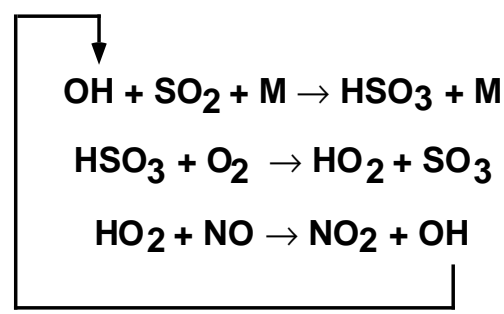

Figure 9. In flue gas treatment by non-thermal plasmas, the $\mathrm{OH}$ radical plays a key role in the simultaneous oxidation of $\mathrm{NO}$ and $\mathrm{SO}_{2}$. The presence of $\mathrm{SO}_{2}$ serves to lower the energy cost for oxidation of $\mathrm{NO}$ by converting $\mathrm{OH}$ to $\mathrm{HO}_{2}$; the $\mathrm{OH}$ radical is then reproduced when $\mathrm{NO}$ is oxidized by $\mathrm{HO}_{2}$. 
In discharge reactors, because the electron mean energy is relatively low, the $\mathrm{OH}$ radicals are produced via three types of reactions:

Electron attachment: e $+\mathrm{H}_{2} \mathrm{O} \rightarrow \mathrm{H}^{-}+\mathrm{OH}$

Direct dissociation by electron impact: e $+\mathrm{H}_{2} \mathrm{O} \rightarrow \mathrm{e}+\mathrm{H}+\mathrm{OH}$

Dissociation by $\mathrm{O}\left({ }^{1} \mathrm{D}\right): \mathrm{O}\left({ }^{1} \mathrm{D}\right)+\mathrm{H}_{2} \mathrm{O} \rightarrow 2 \mathrm{OH}$

In electron beam reactors, because the primary electron energy is high, the $\mathrm{OH}$ radicals come mainly from the positive ions reacting with $\mathrm{H}_{2} \mathrm{O}$. The sequence of steps are as follows:

Electron-impact ionization: $\mathrm{e}+\mathrm{O}_{2} \rightarrow 2 \mathrm{e}+\mathrm{O}_{2}{ }^{+}$

and similar ionization processes to produce molecular ions: $\mathrm{N}_{2}{ }^{+}, \mathrm{H}_{2} \mathrm{O}^{+}, \mathrm{CO}_{2}{ }^{+}$

Electron-impact dissociative ionization: $\mathrm{e}+\mathrm{O}_{2} \rightarrow 2 \mathrm{e}+\mathrm{O}+\mathrm{O}^{+}$

and similar dissociative ionization processes to produce $\mathrm{N}^{+}, \mathrm{H}^{+}$

Charge transfer reactions to form additional $\mathrm{O}_{2}{ }^{+}$ions, such as:

$$
\mathrm{N}_{2}^{+}+\mathrm{O}_{2} \rightarrow \mathrm{N}_{2}+\mathrm{O}_{2}{ }^{+}
$$

Formation of water cluster ions: $\mathrm{O}_{2}^{+}+\mathrm{H}_{2} \mathrm{O} \rightarrow \mathrm{O}_{2}^{+}\left(\mathrm{H}_{2} \mathrm{O}\right)$

Dissociative reactions of water cluster ions to form $\mathrm{OH}$ :

$$
\begin{aligned}
& \mathrm{O}_{2}{ }^{+}\left(\mathrm{H}_{2} \mathrm{O}\right)+\mathrm{H}_{2} \mathrm{O} \rightarrow \mathrm{H}_{3} \mathrm{O}^{+}+\mathrm{O}_{2}+\mathrm{OH} \\
& \mathrm{O}_{2}{ }^{+}\left(\mathrm{H}_{2} \mathrm{O}\right)+\mathrm{H}_{2} \mathrm{O} \rightarrow \mathrm{H}_{3} \mathrm{O}^{+}(\mathrm{OH})+\mathrm{O}_{2} \\
& \text { followed by } \\
& \qquad \mathrm{H}_{3} \mathrm{O}^{+}(\mathrm{OH})+\mathrm{H}_{2} \mathrm{O} \rightarrow \mathrm{H}_{3} \mathrm{O}^{+}+\mathrm{H}_{2} \mathrm{O}+\mathrm{OH} .
\end{aligned}
$$

Figure 10 shows the contributions of various processes to the production of $\mathrm{OH}$ radicals as a function of the electron mean energy in an electrical discharge plasma. Note that high electron mean energies are required for maximizing the production of $\mathrm{OH}$ radicals. The use of electron beam processing provides the most economical way of producing $\mathrm{OH}$ radicals, because electron beams are very efficient in producing positive ions.

Recently there has been a growing interest in the application of non-thermal plasmas to the removal of $\mathrm{NO}_{x}$ from diesel engine exhaust gases [29]. The development of a technology for the chemical reduction of $\mathrm{NO}_{\mathrm{x}}$ in oxygen-rich environments would represent a breakthrough in the transportation industry. The implication of such a technology is far reaching for mobile sources since it will allow fuel-efficient, lean-burn gasoline and diesel engines to be developed that decrease $\mathrm{CO}_{2}$ greenhouse gas emissions yet still permit the reduction of harmful $\mathrm{NO}_{\mathrm{x}}$, carbon monoxide and hydrocarbons. Although such a technology exists for stationary combustion sources, a more feasible, cost-effective and environmentally sound approach for mobile sources does not exist.

Our experiments show that the presence of hydrocarbons promotes only the oxidation of $\mathrm{NO}$ to $\mathrm{NO}_{2}$, but not the reduction of $\mathrm{NO}$ to $\mathrm{N}_{2}$ and $\mathrm{O}_{2}$. The chainoxidation process in the presence of hydrocarbons is shown in Figure 11. Thus the use of hydrocarbon additives may be advisable only for lowering the power consumption of the plasma process in stationary combustion sources for which scrubbing of byproducts is acceptable. 


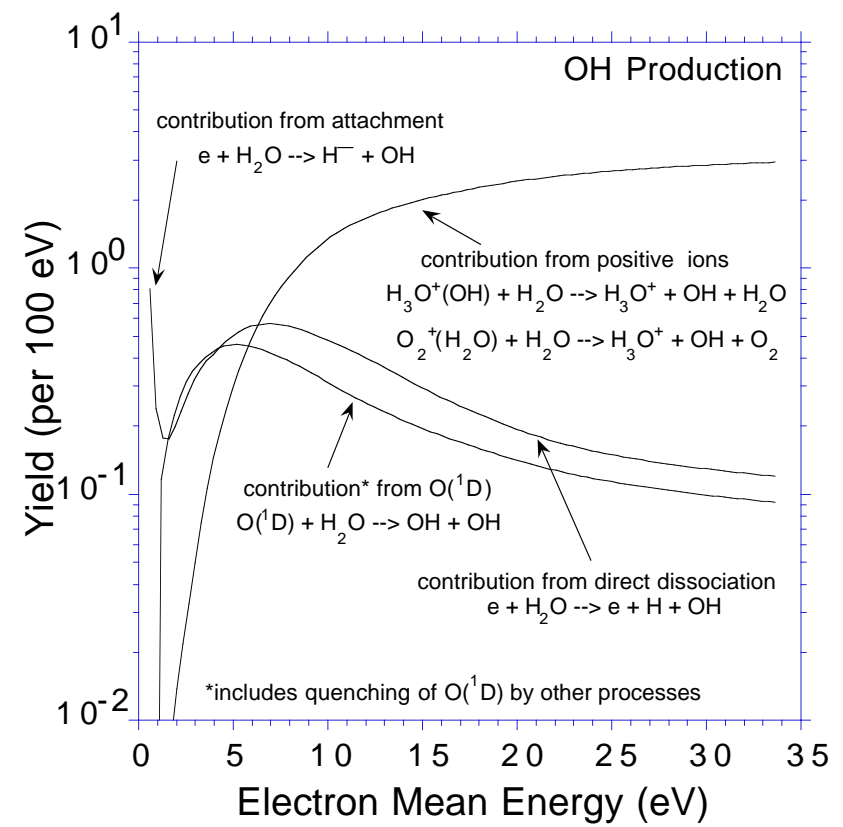

Figure 10. Contributions of various processes to the production of $\mathrm{OH}$ as a function of the electron mean energy in the plasma for a gas mixture of $5 \% \mathrm{O}_{2}, 10 \% \mathrm{H}_{2} \mathrm{O}, 15 \%$ $\mathrm{CO}_{2}$ and $70 \% \mathrm{~N}_{2}$. In electron beam processing, the $\mathrm{OH}$ radicals come mainly from the positive ions reacting with $\mathrm{H}_{2} \mathrm{O}$.

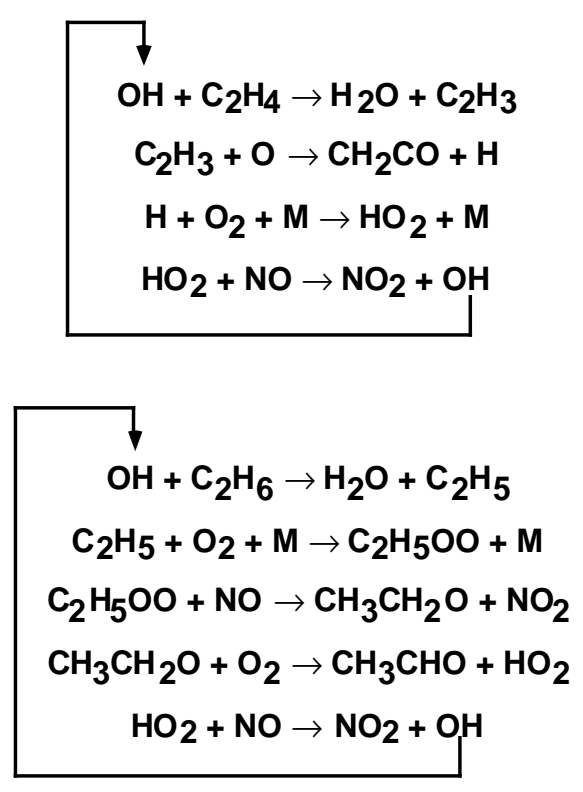

Figure 11. In non-thermal plasma processing at ambient temperature conditions, the presence of hydrocarbons enhances the oxidation of $\mathrm{NO}$ to $\mathrm{NO}_{2}$, but not the reduction of $\mathrm{NO}$ to $\mathrm{N}_{2}$ and $\mathrm{O}_{2}$. 
For mobile engine applications, it is very important to make a distinction between NO removal by chemical oxidation and NO removal by chemical reduction. To avoid the need for scrubbing of process products, the desired method of NO removal is by chemical reduction; i.e. the conversion of NO to the benign products $\mathrm{N}_{2}$ and $\mathrm{O}_{2}$. For typical exhaust gases without additives, the only species that the plasma can produce to implement $\mathrm{NO}$ reduction is the $\mathrm{N}$ atom. The term "NO reduction" refers strictly to the reaction:

$$
\mathrm{N}+\mathrm{NO} \rightarrow \mathrm{N}_{2}+\mathrm{O} \text {. }
$$

The plasma produces $\mathrm{N}$ atoms through electron-impact dissociation of $\mathrm{N}_{2}$ in the exhaust gas:

$$
\mathrm{e}+\mathrm{N}_{2} \rightarrow \mathrm{e}+\mathrm{N}+\mathrm{N} \text {. }
$$

The development of a cost-efficient non-thermal plasma method for implementing electron-impact dissociation of $\mathrm{N}_{2}$ in atmospheric pressure gas streams could therefore potentially lead to a $\mathrm{NO}_{\mathrm{x}}$ reduction technology that works at ambient temperature and does not require additives or catalysts.

Figure 12 shows a comparison between electron beam, pulsed corona and dielectric-barrier discharge processing of $100 \mathrm{ppm}$ of $\mathrm{NO}$ in $\mathrm{N}_{2}$. The concentration of $\mathrm{NO}$ is presented as a function of the input energy density deposited into the gas. In the NO- $\mathrm{N}_{2}$ mixture the removal of $\mathrm{NO}$ is dominated by the reduction reaction $\mathrm{N}+$ $\mathrm{NO} \rightarrow \mathrm{N}_{2}+\mathrm{O}$. These experiments therefore provide a good measure of the electronimpact dissociation rate of $\mathrm{N}_{2}$. Figure 12 shows that the energy consumption for $\mathrm{NO}$ reduction by electron beam processing is six times less than that of pulsed corona or dielectric-barrier discharge processing. The energy density required to reduce $\mathrm{NO}$ is around 20 Joules/liter and 120 Joules/liter by electron beam and electrical discharge processing, respectively. These experiments provide a good measure of the specific energy consumption for electron-impact dissociation of $\mathrm{N}_{2}$. The specific energy consumption obtained by electron beam processing represents the minimum energy cost for $\mathrm{N}_{2}$ dissociation that can be achieved in any type of atmospheric-pressure non-thermal plasma reactor [27, 30-31].

\section{CONCLUSIONS}

There are basically two types of non-thermal atmospheric-pressure plasma reactors: (1) electrical discharge reactors and (2) electron beam reactors. Many different variants of electrical discharge reactor have been proposed. Two of the more extensively investigated types of discharge reactors are based on the pulsed corona and dielectric-barrier discharge. The most mature discharge reactor is the dielectric-barrier discharge reactor used for ozone generation. However, the optimum conditions for ozone generation are not the optimum conditions for VOC destruction or for the chemical reduction of $\mathrm{NO}_{\mathrm{x}}$. We have found that pulsed corona and other types of electrical discharge reactors are most suitable only for processes requiring $\mathrm{O}$ radicals. In electrical discharge reactors, much of the input power goes to dissociation of $\mathrm{O}_{2}$ and wasted in the vibrational excitation of $\mathrm{N}_{2}$. In electron beam reactors, most of the input power goes to the dissociation and 
ionization of $\mathrm{N}_{2}$. For pollution control applications requiring copious amounts of electrons, ions, $\mathrm{N}$ atoms or $\mathrm{OH}$ radicals, the use of electron beam reactors is generally the best way of minimizing the electrical power consumption.

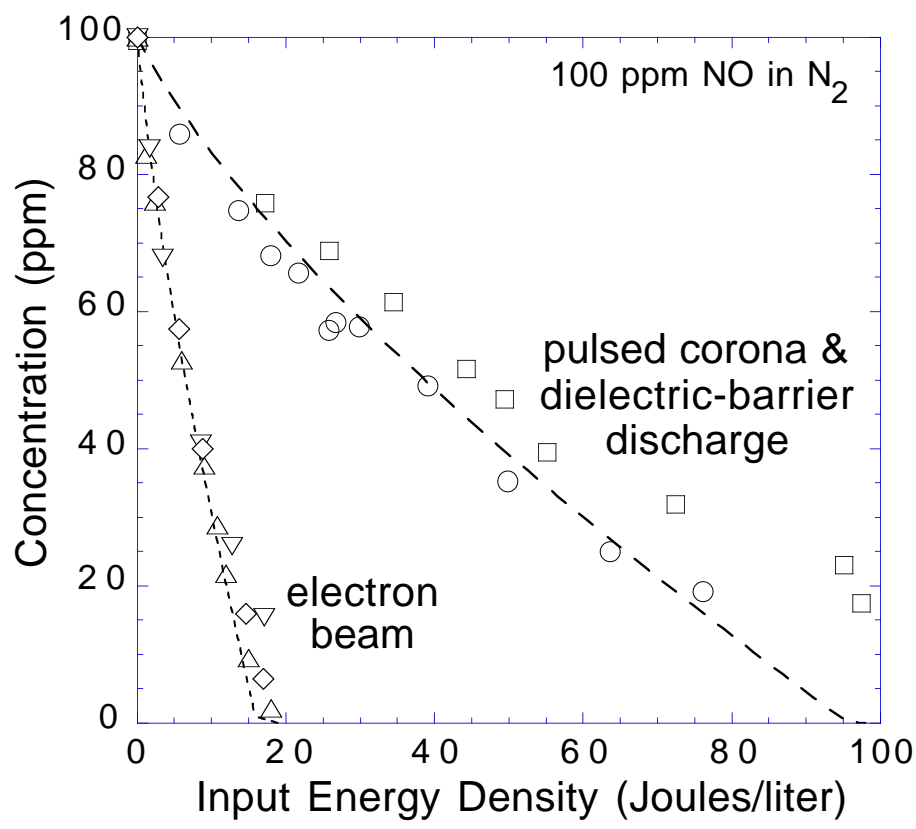

Figure 12. Electron beam, pulsed corona and dielectric-barrier discharge processing of $100 \mathrm{ppm} \mathrm{NO}$ in $\mathrm{N}_{2}$. There is no significant difference in the performance of different types of electrical discharge reactors. Electron beam processing is six times more energy efficient compared to electrical discharge processing in reducing NO. Circle: pulsed corona; square: dielectric-barrier discharge; triangle: $125 \mathrm{keV}$ electron beam with $8.7 \mathrm{lpm}$ gas flow; diamond: $125 \mathrm{keV}$ electron beam with $66 \mathrm{lpm}$ gas flow; inverted triangle: $1.5 \mathrm{MeV}$ electron beam with $2.4 \mathrm{lpm}$ gas flow.

\section{ACKNOWLEDGMENTS}

This work was performed in part at Lawrence Livermore National Laboratory under the auspices of the U.S. Department of Energy under Contract Number W7405-ENG-48, with support from the Chemical Sciences Division of the Office of Energy Research. The electron beam processing equipment was developed under a National Science Foundation SBIR grant, Contract Number III-9122767. 


\section{REFERENCES}

[1] A collection of papers on various types of non-thermal plasma reactors being investigated for VOC and $\mathrm{NO}_{\mathrm{x}}$ abatement appears in Non-Thermal Plasma Techniques for Pollution Control: Part A - Overview, Fundamentals and Supporting Technologies, edited by B. M. Penetrante and S. E. Schultheis (Springer-Verlag, Heidelberg, 1993) and Non-Thermal Plasma Techniques for Pollution Control: Part B - Electron Beam and Electrical Discharge Processing, edited by B. M. Penetrante and S. E. Schultheis (Springer-Verlag, Heidelberg, 1993).

[2] T. Yamamoto, K. Ramanathan, P. A. Lawless, D. S. Ensor, J. R. Newsome, N. Plaks, G. H. Ramsey, C. A. Vogel, and L. Hamel, IEEE Trans. on Ind. Appl. 28, 528 (1992); T. Yamamoto, P. A. Lawless, M. K. Owen, D. S. Ensor, and C. Boss, in Non-Thermal Plasma Techniques for Pollution Control: Part B - Electron Beam and Electrical Discharge Processing, edited by B. M. Penetrante and S. E. Schultheis (Springer-Verlag, Heidelberg, 1993) pp. 223-238.

[3] M. C. Hsiao, B. T. Merritt, B. M. Penetrante, G. E. Vogtlin, and P. H. Wallman, J. Appl. Phys. 78, 3451 (1995).

[4] D. Evans, L. A. Rosocha, G. K. Anderson, J. J. Coogan, and M. J. Kushner, J. Appl. Phys. 74, 5378 (1993); L. A. Rosocha, G. K. Anderson, L. A. Bechtold, J. J. Coogan, H. G. Heck, M. Kang, W. H. McCulla, R. A. Tennant, and P. J. Wantuck, in Non-Thermal Plasma Techniques for Pollution Control: Part B Electron Beam and Electrical Discharge Processing, edited by B. M. Penetrante and S. E. Schultheis (Springer-Verlag, Heidelberg, 1993) pp. 281-308.

[5] W. C. Neely, E. I. Newhouse, E. J. Clothiaux, and C. A. Gross, in Non-Thermal Plasma Techniques for Pollution Control: Part B-Electron Beam and Electrical Discharge Processing, edited by B. M. Penetrante and S. E. Schultheis (SpringerVerlag, Heidelberg, 1993) pp. 309-320; E. I. Newhouse, W. C. Neely, E. J. Clothiaux, and J. W. Rogers, in ACS Symposium on Emerging Technologies in Hazardous Waste Management VI, pp. 207-210; E. J. Clothiaux, J. A. Koropchak, and R. R. Moore, Plasma Chem. Plasma Process. 4, 15 (1984).

[6] M. E. Fraser, D. A. Fee, and R. S. Sheinson, Plasma Chem. Plasma Process. 5, 163 (1985); M. E. Fraser and R. S. Sheinson, Plasma Chem. Plasma Process. 6, 27 (1986).

[7] S. Masuda, in Non-Thermal Plasma Techniques for Pollution Control: Part B Electron Beam and Electrical Discharge Processing, edited by B. M. Penetrante and S. E. Schultheis (Springer-Verlag, Heidelberg, 1993) pp. 199-210; T. Oda, T. Takahashi, H. Nakano, and S. Masuda, in Proceedings of the 1991 IEEE Industrial Application Society Meeting (Dearborn, MI, September/October 1991) pp. 734-739.

[8] A. Czernichowski and H. Lesueur, in Proceedings of the 10th International Symposium on Plasma Chemistry (Bochum, Germany, 1991); A. Czernichowski and $\mathrm{T}$. Czech, in Proceedings of the 3rd International Symposium on High-Pressure Low-Temperature Plasma Chemistry (Strasbourg, France, 1991). 
[9] L. J. Bailin, M. E. Sibert, L. A. Jonas, and A. T. Bell, Environ. Sci. Tech. 9, 254 (1975).

[10] K. Kawamura, S. Aoki, H. Kimura, K. Adachi, T. Katayama, K. Kengaku and Y. Sawada, Environ. Sci. Tech. 14, 288 (1980).

[11] O. Tokunaga and N. Suzuki, Radiat. Phys. Chem. 24, 145 (1984).

[12] N. Frank, S. Hirano and K. Kawamura, Radiat. Phys. Chem. 31, 57 (1988).

[13] A. Maezawa and M. Izutsu, in Non-Thermal Plasma Techniques for Pollution Control: Part B - Electron Beam and Electrical Discharge Processing, edited by B.M. Penetrante and S.E. Schultheis (Springer-Verlag, Heidelberg, 1993) pp. 4754.

[14] R. C. Slater and D. H. Douglas-Hamilton, J. Appl. Phys. 52, 5820 (1981).

[15] H. Scheytt, H. Esrom, L. Prager, R. Mehnert, and C. von Sonntag, in NonThermal Plasma Techniques for Pollution Control: Part B - Electron Beam and Electrical Discharge Processing, edited by B. M. Penetrante and S. E. Schultheis (Springer-Verlag, Heidelberg, 1993) pp. 91-102.

[16] S. M. Matthews, A. J. Boegel, J. A. Loftis, R. A. Caufield, B. J. Mincher, D. H. Meikrantz, and R. J. Murphy, Radiat. Phys. Chem. 42, 689 (1993).

[17] S. A. Vitale, K. Hadidi, D. R. Cohn, P. Falkos and L. Bromberg, "Trichloroethylene and 1,1,1-Trichloroethane Decomposition in an Electron Beam Generated Plasma Reactor", paper presented at the I\&EC Special Symposium of the American Chemical Society, Atlanta, GA, September 17-20, 1995.

[18] L. Bromberg, D. R. Cohn, M. Kock, R. M. Patrick, and P. Thomas, Phys. Lett. A 173, 293 (1993); M. Koch, D. R. Cohn, R. M. Patrick, M. P. Schuetze, L. Bromberg, D. Reilly and P. Thomas, Phys. Lett. A 184, 109 (1993).

[19] B. M. Penetrante, M. C. Hsiao, B. T. Merritt, G. E. Vogtlin, P. H. Wallman, A. Kuthi, C. P. Burkhart and J. R. Bayless, Phys. Lett. A 209, 69 (1995).

[20] B. M. Penetrante, M. C. Hsiao, J. N. Bardsley, B. T. Merritt, G. E. Vogtlin, P. H. Wallman, A. Kuthi, C. P. Burkhart and J. R. Bayless, Pure \& Appl. Chem. 68, 1083 (1996).

[21] H.-R. Paur, in Non-Thermal Plasma Techniques for Pollution Control: Part B Electron Beam and Electrical Discharge Processing, edited by B.M. Penetrante and S.E. Schultheis (Springer-Verlag, Heidelberg, 1993) pp. 77-90.

[22] "Low-Cost Sealed-Tube Electron Beam Gun", in RED Magazine, September 1995, p. 51.

[23] W. L. Morgan and B. M. Penetrante, Comp. Phys. Comm. 58, 127-152 (1990).

[24] B. M. Penetrante and J. N. Bardsley, J. Appl. Phys. 66, 1871-1874 (1989).

[25] R. J. Kee, F. M. Rupley and J. A. Miller, "Chemkin-II: A FORTRAN Chemical Kinetics Package for the Analysis of Gas Phase Chemical Kinetics," Sandia National Laboratories Report No. SAND89-8009B UC-706 (April 1992).

[26] B. Eliasson and U. Kogelschatz, J. Phys. B: At. Mol. Phys. 19, 1241 (1986). 
[27] B. M. Penetrante, M. C. Hsiao, B. T. Merritt, G. E. Vogtlin and P. H. Wallman, IEEE Trans. Plasma Sci. 23, 679 (1995).

[28] R. M. Patrick and K. Hadidi, "An Electron Beam Plasma System for Halogenated Hydrocarbon Vapor Destruction", Paper \# 95-WP77B.04, 88th Annual Meeting \& Exhibition of the Air \& Waste Management Association, San Antonio, TX (18-23 June 1995).

[29] M. Higashi, S. Uchida, N. Suzuki and K. Fujii, IEEE. Trans. Plasma Sci. 20, 1 (1992).

[30] B. M. Penetrante, M. C. Hsiao, B. T. Merritt, G. E. Vogtlin, P. H. Wallman, M. Neiger, O. Wolf, T. Hammer and S. Broer, Appl. Phys. Lett. 68, 3719-3721 (1996).

[31] B. M. Penetrante, M. C. Hsiao, B. T. Merritt, G. E. Vogtlin, P. H. Wallman, A. Kuthi, C. P. Burkhart and J. R. Bayless, Appl. Phys. Lett. 67, 3096-3098 (1995). 


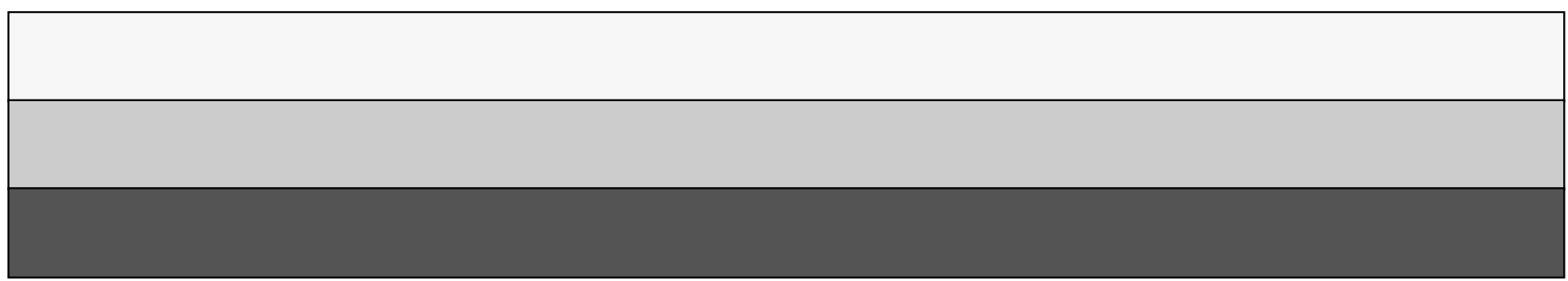

